\title{
Factors Associated with Stress among Nursing Students in Pokhara
}

\author{
Keshav Lamichhane
}

\begin{abstract}
This study aims to find the factors associated with stress among nursing students in Pokhara. For this purpose, information was collected from all the one hundred ten nursing students studying proficiency certificate level in Charak Academy, Pokhara by using structured questionnaire. A purposive sampling technique was applied to collect data from all the nursing students. Chi-square test was applied to find the factors associated with stress.

Univariate analysis shows that the stress is low among PCL third year students while stress is high among first- and second-year students. More than half of the students have low stress among nurses in age group 17-21year as compared to 60 percent to nurses in age group 22-25 year. Likewise, the level of stress is high among nurses from nuclear family $\mathbf{5 2 . 8 \% )}$ as compared as $\mathbf{2 3 . 8 \%}$ nurses in joint family.

Bivariate analysis (chi square) shows that the majority of the variables are not significantly related to the stress, however educational level and family type are found significantly related to the stress among the nurses.
\end{abstract}

Index Terms - Stress, Nurses, Pokhara.

\section{INTRODUCTION}

Stress can be regarded as a psychological threat, in which the individual perceives a situation as a potential threat. ${ }^{1}$ It is a condition in which the person responds to changes in the normal balance state. Stress is a part and parcel of human lifestyle. It can serve as a driving force in terms of obtaining results, but on the other hand, non-stop stress can act as a killer in terms of performance. ${ }^{2}$

Stressors can be broadly defined as situations or events that have the potential to affect health outcomes and cause an individual to experience stress whereas perceivedstress isdefined as the degree to which a situation in one's life is deemed stressful. ${ }^{3}$

It is a known fact that students are subjected to different kinds of stressors, such as the pressure of academics with an obligation to succeed, an uncertain future, and difficulties of integrating into the system. ${ }^{4}$

Nursing is a profession which came into existence during the Crimean war and is continuing till date. Nursing students constitute the backbone of the nursing profession. ${ }^{5}$ Entering the world of nursing presents the new students with a fearsome array of changes. Often still in their teens they are often asked to transform from adolescent to adult and from lay person to professional. ${ }^{6}$

Stress is a factor that happens to affect everyone's life. Nursing students undergo tremendous stress during various stages of their course..$^{7}$ Studies comparing the stress levels of various professional students found that nursing students especially during $1^{\text {st }}$ year experience higher levels of stress

Keshav Lamichanne, Department of Statistics,Prithivi Narayan Campus,Pokhara,Nepal than medical, social work and pharmacy students ${ }^{8}$. Another study conducted in North India on 2013to assess perceived stress in the undergraduate students studying in a nursing college located in North India by using perceived stress scale among the sample $n=282$ students both male and female. Female students had more perceived stress score (31.33) than male students (26.01). The maximum mean perceived stress score (29.66) was observed in $2^{\text {nd }}$ year students, and the least mean perceived stress score (26.28) was found in 3rd year students. $^{9}$

College students experience high stress at predictable times each year due to academic commitments, financial pressures and lack of time management skills. Moreover, these stressors do not cause anxiety or tension by themselves. Instead, stress results from the interaction between stressors and the individual's perception and that stressors will show the reaction. The common sources of stress for college students include excessive homework, unclear assignments, and uncomfortable classrooms. In addition to academic requirements, relations with faculty members and time pressures may also be sources of stress. ${ }^{10}$

The unmanaged stress will lead to addictive behaviors, relationship distress, and emotional/behavioral problems. Loss or lack of spirituality, academic consequences, changes in mood-sadness, irritability, futility, hopelessness, angry, frustration, and anxiety. ${ }^{11}$ Such person shows the symptoms like low mood, loss of interest, enjoyment and reduced energy. Their sleep, appetite and concentration may also be affected. $^{12}$

The World Health Organization (WHO) has estimated that stress-related disorders will be one of the leading causes of disability by the year $2020 .^{13}$

\section{RESEARCH METHODOLOGY}

Purposive sampling methods were applied, nursing student of Charak Academy, Pokhara, Nepal was considered as sampling framework. Altogether 110 nursing students studying in different Proficiency certificate level were interviewed with standardized COHEN PERCEIVED STRESS SCALE and self-administered questionnaire. The tool consist of two parts. Part I: Socio- demographic information. Part II: Standard Sheldon Cohen Perceived Stress Scale questionnaire. Contains 10 questions each allowing respondent to mark their perception ranging from 0 to 4 , PSS scores are obtained by reversing responses (e.g., $0=$ $4,1=3,2=2,3=1 \& 4=0$ ) to the four positively stated items (items $4,5,7, \& 8$ ) and then summing across all scale items. Perceived Stress Scale Score $(\mathrm{k})=\Sigma \mathrm{Qij}, \mathrm{i}=1-10$, $\mathrm{j}=0,1,2,3,4$

Univariate and Bivariate analysis were performed with SPSS 20 


\section{RESULT}

\section{A. Sample Representation}

Altogether 110 students were surveyed, the majority of respondents belong to the age group 17-21years which accounts 100 of total respondents. Most of them are Hindu 92 out of 110. Majority of the respondents are unmarried with a number of 108 and only the 11 were married. No one among the respondents is divorced. Similarly 115 respondents have no child where only 4 respondents have single child. In family type 89 respondents are from nuclear family and 21 are from joint family. Most of them i.e. 58 respondents stay at their own home and 52 respondents stay at collage's hostel. Educational level of respondents is 38 from both Proficiency Certificate Level first and 37 from second year and 35 from third year respectively. According to the respondents no one participate in stress management training.

Table 1. General characteristics of respondent.

\begin{tabular}{|l|l|}
\hline Age & Number (percentage) \\
\hline $17-21$ & $100(91)^{*}$ \\
\hline $22-25$ & $10(9)$ \\
\hline Religion & $92(84)$ \\
\hline Hindu & $7(6)$ \\
\hline Christian & $11(10)$ \\
\hline Buddhism & \\
\hline Marital Status & $99(90)$ \\
\hline Unmarried & $11(10)$ \\
\hline Married & \\
\hline Family type & $89(81)$ \\
\hline Nuclear & $21(19)$ \\
\hline Joint & \\
\hline Place of living & $52(47)$ \\
\hline Hostel & $58(53)$ \\
\hline Home & \\
\hline Education & $38(34)$ \\
\hline PCL 1st Year & $37(34)$ \\
\hline PCL 2nd Year & $35(32)$ \\
\hline PCL 3rd Year &
\end{tabular}

* Number on parenthesis represents percentage.

\section{B. Mean Response of perception}

It has been observed that, nurses have low confident on their ability to handle personnel problem (1.4 \pm 1.2$)$ On an average they scored their feeling of nervousness and stressed as 2.7 out of 4. (Table 2)

Table 2: Mean response of perception

\begin{tabular}{|l|c|}
\hline $\begin{array}{l}\text { In the last month, how often have } \\
\text { you................... }\end{array}$ & Mean \pm SD \\
\hline $\begin{array}{l}\text { been upset because of something that } \\
\text { happened unexpectedly? }\end{array}$ & $2.4 \pm 1.1$ \\
\hline $\begin{array}{l}\text { you felt that you were unable to control the } \\
\text { important things in your life? }\end{array}$ & $2.2 \pm 1.1$ \\
\hline $\begin{array}{l}\text { you felt nervous and "stressed"? } \\
\begin{array}{l}\text { you felt confident about your ability to } \\
\text { handle your personal problems? }\end{array}\end{array}$ & $2.7 \pm 0.9$ \\
\hline $\begin{array}{l}\text { you felt that things were going your way? } \\
\text { you found that you could not cope with all the }\end{array}$ & $1.4 \pm 1.2$ \\
\hline
\end{tabular}

\begin{tabular}{|l|l|}
\hline things you had to do? & \\
$\begin{array}{l}\text { you been able to control irritations in your } \\
\text { life? }\end{array}$ & $2.0 \pm 1.3$ \\
\hline $\begin{array}{l}\text { you felt that you were on top of things? } \\
\begin{array}{l}\text { you been angered because of things that were } \\
\text { outside of your control? }\end{array}\end{array}$ & $2.3 \pm 1.2$ \\
\hline $\begin{array}{l}\text { you felt difficulties were piling up so high } \\
\text { that you could not overcome them? }\end{array}$ & $2.4 \pm 1.0$ \\
\hline
\end{tabular}

\section{Perceived Stress Scale Score (PSS) on Nursing Student against different characteristics}

Stressed score are found to be high and scattered on age group of 17 to 21 in comparison to the 22 to 25 years age group nurses. Nurses following Christianity are found to have high stressed whereas Buddhist followers are less stressed. Similarly, unmarried are high stressed than that of married ones. Whereas the Nuclear family membered nurses are higher stressed than that of joint family. Nurses studying on PCL $1^{\text {st }}$ year are highly stressed whereas nurses on $3^{\text {rd }}$ year are low stressed. The difference on stress level on family type and education level are significantly different. (Table 3)
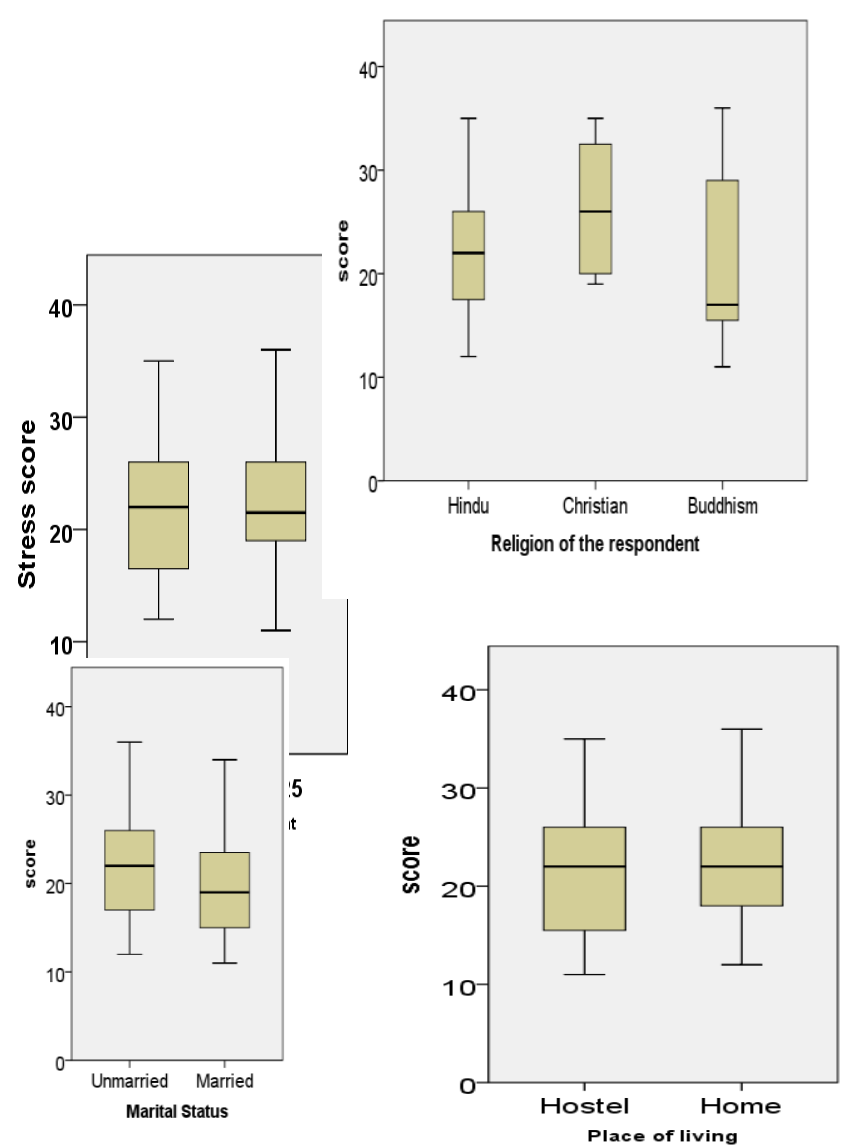
Table 3: Association on Nursing Students StressLevel

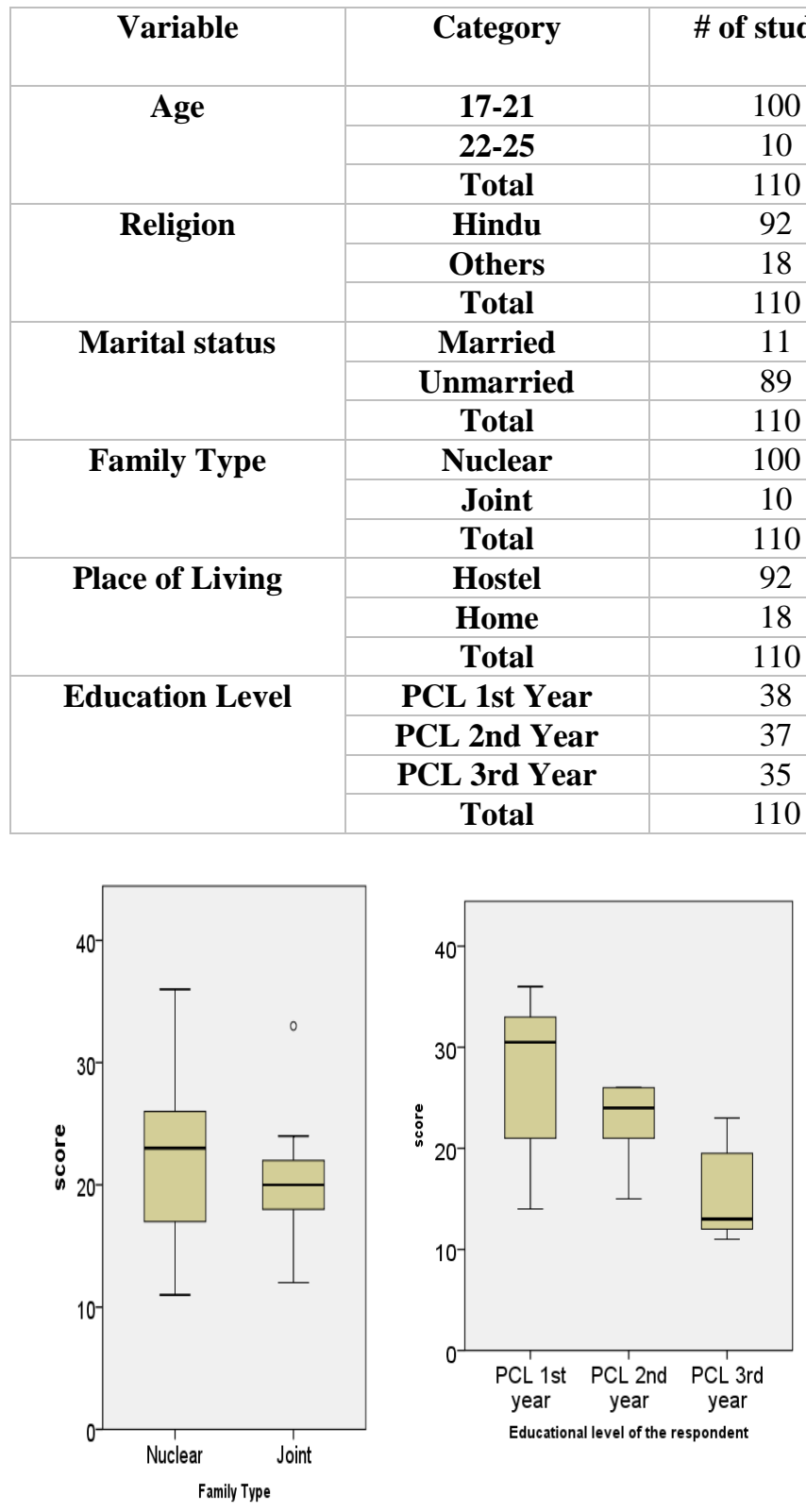

\section{DISCUSSION}

Nursing is a noble profession. They are expected to perform with task in stress free environment. The result shows stress are related to education level. Similar result was observed onstudy on Stress/Stressors as perceived by Nepalese Nursing Students in Pokhara Manipal Collage Of Medical Science on 2014 among B.Sc and PCL students that there is association between stressors and educational status but there was no association between Stressors and other variables. In contradiction to the no association with other variable, this study shows that there exist association with family size and stress level of the students.

Stress may affect students' lives. In addition, it may but may also not good for patient care in the long run. We need to continue to be attentive to the well- being of medical students, particularly in the face of rising living costs, uncertain career, career choice and other factors. More programs should be carried out to promote the students

\begin{tabular}{|c|c|c|}
\hline \multicolumn{2}{|c|}{$\%$ of student on Stress Level } & \multirow[t]{2}{*}{ P Value } \\
\hline Low $(<22)$ & $\operatorname{High}(>22)$ & \\
\hline 52 & 48 & \multirow[t]{2}{*}{0.629} \\
\hline 60 & 4 & \\
\hline 58 & 52 & \multirow{3}{*}{0.793} \\
\hline 52 & 48 & \\
\hline 56 & 44 & \\
\hline 53 & 47 & \multirow{3}{*}{0.161} \\
\hline 73 & 27 & \\
\hline 51 & 49 & \\
\hline 53 & 47 & \multirow{3}{*}{$0.017 *$} \\
\hline 52 & 48 & \\
\hline 60 & 4 & \\
\hline 58 & 52 & \multirow{3}{*}{0.873} \\
\hline 52 & 48 & \\
\hline 56 & 44 & \\
\hline 53 & 47 & \multirow{4}{*}{$0.001 *$} \\
\hline 34 & 66 & \\
\hline 32 & 68 & \\
\hline 94 & 6 & \\
\hline 53 & 47 & \\
\hline
\end{tabular}

well-being, conducting stress related programs, providing training about coping mechanisms and developing coping tools to deals with the stress throughout their undergraduate, postgraduate training and professional life ${ }^{21}$ So appropriate attention should be paid to them from all levels and assure them for their job as well as better future to overcome their frustration. Delaying in minimizing stressful life events is associated with more damage to the students. Therefore researcher hope that a assessment of perceived stress among nursing students will help to find out the causes of stress and suggest for appropriate action in future.$^{22}$

The stress management counseling classes during the study period would help the students to grow up in stress free environment and enjoy the profession which will beautify the relation with the patients.

\section{CONCLUSION}

The stress is low among PCL third year students while stress is high among first and second year students. As the number of years of study increases the students cope with the stress and level of stress decreases. Students on $1^{\text {st }}$ and $2^{\text {nd }}$ years have to be provided counseling and trainings on stress management. More than half of the students have low stress among nurses in age group 17-21 year as compared to 60 percent nurses in age group 22-25 year. Likewise the level of stress is high among nurses from nuclear family (52.8\%)as compared as $23.8 \%$ nurses in joint family.

The stress level on nursing student is significantly different on year of study and family type they belong.

\section{REFERENCES}

[1] Evans W, Kelly B. Pre-registration diploma student nurse stress and coping measures. Nurse Education Today [Internet][cited 2004 Aug 24]; (6): 473-82. $\quad$ Available :http://dx.doi.org/10.1016/j.nedt.2004.05.004 PMid:15312957

[2] Barling J. Employment, stress and family functioning. New York: John Wiley \& Sons; 1990. 
[3] Day AL, Livingstone HA. Gender differences in perceptions of stressors and utilization of social support among university students. Canadian Journal of Behavioural Science. [Internet] 2003[cited 2004];35(2):73-83.

[4] Oraon P, Saini R. Understanding the problems faced by the nursing students. Health Action 2009 Apr; 4.

[5] Nisha G. A study to assess the effectiveness of mindfulness meditation technique on stress reduction among first year b. Sc. Nursing students in a selected nursing college at Mangalore.[Internet]2011available from www.rguhs.ac.in/cdc/onlinecdc/uploads/05_N153_30008.doc

[6] Dhar N, Nandan D. Stress - a public health menace of the day Combat it 2008, National Institute of Health and Family Welfare. [Last accessed on 8 Apr 2012]. Available from: http://www.nihfw.org/Publications/News letter.html .

[7] Kumar S, Dagli RJ, Mathur A, Jain M, Prabu D, Kulkarni S. Perceived sources of stress amongst Indian dental students. Eur J Dent Educ. 2009;13:39-45. [PubMed]

[8] Lamk AL. Stress in the Medical Profession and its roots in Medical School. SQU Med J. 2010;10:156-9. [PMC free article] [PubMed]

[9] Sherina MS, Rampal L, Kaneson N. Psychological Stress Among Undergraduate Medical Students. Med J Malaysia. 2004;59:207-11. [PubMed]

[10] Deary IJ, Watson R, Hogston R. A longitudinal cohort study of burnout and attrition in nursing students. J Adv Nurs. 2003;43:71-81. [PubMed]

[11] Sharma N, Kaur A. Factors associated with stress among nursing students. Nurs Midwifery Res J. 2011;7:12-21.

[12] Agolla JE, OngoriH.An assessment of academic stress among undergraduate students. The case of University of Botswana, Educational Research and Preview. 2009; Vol .4(2) pp 063-070. Available online at http://www.academicjournals.org/ERR

[13] TrockelM.Barnes $\bar{M}$ \&EGGet D. Health -related Variables and academic performance among first year collage students: implications for sleep and other behaviors, Journal of American Collage Health .2000;49(3):125-132.

[14] Pryjmachuk S, Richards DA. Predicting stress in Pre-registration nursing students.British Journal of Health psychology. 2007; 12(1),125-144

[15] Rella S, Winwood PC \&Lushington, K. When does nursing burnout begin? An investigation on the fatigue experience of Australian nursing students. Journal of Nursing management. 2008;17,886-897. 